\title{
Comunicação
}

\section{Freqüência de adenocarcinomas em derrames cavitários}

\author{
A. Longatto Filho, H. Bisı, J. Bortolan, V. Lombardo, V. A. F. Alves \\ Trabalho realizado pela Divisão de Patologia do I nstituto Adol fo Lutz, São Paulo, SP.
}

RESUMO - Objetivo. I dentificação de freqüência de adenocarcinomas de diferentes sítios primários em derrames cavitários.

Material e Métodos. Foram estudados 2.317 casos: 1.146 de derrame pleural (943 mulheres e 203 homens), 1.168 de ascite (727 mulheres e 441 homens) e três de pericárdio (duas mulheres e um homem) e realizada análise retrospectiva dos prontuários dos pacientes e correlação dos achados clínico-laboratoriais.

Resultados. Os sítios primários mais freqüentes em derrames pleurais foram: mama ( $N=586$ 51,1\%), pulmão ( $N=185$ - 16,1\%: 102 homens e 83 mulheres), ovário ( $N=124-10,8 \%$ ); em ascites: estômago ( $N=473$ - 40,5\%: 300 homens e 173 muIheres), ovário ( $N=306-26.2 \%$ ) e mama ( $N=83$ 7,1\%). Desses, 555 casos foram citologicamente positivos para malignidade em derrames pleu-

\section{NTRODUÇÃO}

O diagnóstico citológico de neoplasias pelo achado de al terações celulares em derrames cavitári os vem sendo realizado há mais de um sécul o ${ }^{1}$, e seu valor diagnóstico tem recebido constante atenção da literatura científica, através de várias décadas. É um método de alta especifici dade diagnóstica e poder, em muitas ocasiões, identificar padrões histogenéticos das neoplasias, sugerindo sítios primários e, em algumas situações, conter um significado intrínseco em relação ao prognóstico dos pacientes ${ }^{2-11}$, além de monitorar experimentos em relação à biologia das neoplasias ${ }^{12}$, ou acompanhar eventuais derrames secundários à radioterapia ${ }^{13}$.

Critérios morfológi cos têm sido exaustivamente revistos com o objetivo de se otimi zar as aplicações acima mencionadas, diminuindo os índices de resultados falsos, tanto negativos quanto positi$\operatorname{vos}^{9,14}$. Apesar disso, a sensibilidade da citologia ainda é baixa em relação a seus altos índices de especificidade ${ }^{15}$.

Devido à falta de um centro mundial de registro de câncer, com dados minuciosos de cada país sobre incidência, mortalidade e características de rais, 541 em ascite e dois em pericárdio. Os sítios primários mais freqüentes em derrames pleurais citologicamente positivos foram: mama ( $N=288$ 51,9\%), pulmão ( $N=92,16,6 \%: 45$ homens e 47 muIheres) e ovário ( $N=54,9,7 \%)$; e, em ascites: ovário ( $N=205$ - 37,9\%), estômago ( $N=202,37,3 \%: 119$ homens e 83 mulheres) e mama ( $N=31$ - 6,8\%). E m 47 derrames pleurais (8,5\%) e 37 ascites $(6,8 \%)$, a origem dos adenocarcinomas persistiu indeterminada.

Conclusão. As freqüências estabelecidas poderão, em associação a dados clínicos,orientar a investigação dos sítios primários de adenocarcinomas metastáticos.

Unitermos: Adenocarcinoma. Derrames serosos. Citopatologia. Derrame pleural. Ascite. Metástase.

freqüência de cada tipo neoplásico, é impossível projetar uma imagem uniforme das várias casuísticas estudadas. Por isso, as variáveis obtidas nos vári os relatos carecem de muitas informações para se traçar um perfil específico do comportamento bi ológi co dos cânceres de cada população analisada ${ }^{16}$. Pode-se especular que as variações, por exemplo, de incidência de determinados tipos neoplásicos em derrames ocorram devido às características inerentes dos grupos estudados, ou ao procedimento da conduta clínica das muitas equipes médicas que, eventualmente, possam não solicitar análise citológica de um derrame que apresente outros sinais de comprometimento neoplásico.

Um traço comum a todos os relatos refere-se à importante incidência de neoplasias metastáticas em derrames de sítio primário desconhecido ${ }^{17,18}$. $46 \%$ a $64 \%$ dos pacientes com derrames neoplási cos não têm conhecimento prévio do sítio primário das neoplasias ${ }^{19,20}$.

A maior parte desses carcinomas de sítio primário desconhecido apresentam padrão histológico de adenocarcinoma9,18. Os adenocarcinomas são, em geral, as neoplasias mais comumente encontradas nos derrames cavitári os ${ }^{21,22}$. Devido às dificuldades em se estabelecer o reconhecimento do 


\begin{tabular}{|c|c|c|c|}
\hline \multirow[b]{2}{*}{ Sítio } & \multirow[b]{2}{*}{ Total } & \multicolumn{2}{|c|}{ Diagnóstico Citológico } \\
\hline & & Positivo & Negativo \\
\hline Primário & $\mathbf{N}(\%)$ & N (\%) & $\mathbf{N}(\%)$ \\
\hline Mama & $586(51,1)$ & $288(51,9)$ & $298(50,4)$ \\
\hline Pulmão & $185(16,1)$ & $92(16,6)$ & $93(15,7)$ \\
\hline Ovário & $124(10,8)$ & $54(9,7)$ & $70(11,8)$ \\
\hline Indeterminado & $73(6,4)$ & $47(8,5)$ & $26(4,4)$ \\
\hline Pâncreas & $40(3,5)$ & $11(20,0)$ & $29(4,9)$ \\
\hline Intestino & $28(2,4)$ & $10(1,8)$ & $18(3,0)$ \\
\hline Estômago & $20(1,7)$ & $19(3,4)$ & $1(0,2)$ \\
\hline Endométrio & $17(1,5)$ & $7(1,3)$ & $10(1,7)$ \\
\hline Fígado & $15(1,3)$ & $3(0,5)$ & $12(2,0)$ \\
\hline Rim & $14(1,2)$ & $7(1,3)$ & $7(1,2)$ \\
\hline Via Biliar & $13(1,1)$ & $5(0,9)$ & $8(1,4)$ \\
\hline Próstata & $9(0,8)$ & $1(0,2)$ & $8(1,4)$ \\
\hline Tireóide & $7(0,6)$ & $4(0,7)$ & $3(0,5)$ \\
\hline Colo Uterino & $4(0,3)$ & $1(0,2)$ & $3(0,5)$ \\
\hline Adrenal & $3(0,3)$ & $1(0,2)$ & $2(0,3)$ \\
\hline Esôfago & $3(0,3)$ & $2(0,4)$ & $1(0,2)$ \\
\hline Parótida & $3(0,3)$ & $1(0,2)$ & $2(0,3)$ \\
\hline Tuba Interina & $2(0,2)$ & $2(0,4)$ & 0 \\
\hline Total & $1146(100,0)$ & $555(100,0)$ & $591(100,0)$ \\
\hline
\end{tabular}

Tabela 3-Freqüência de derrames cavitários associados a adenocarcinomas em mulheres distribuídos por sítios primários.

\begin{tabular}{|c|c|c|c|c|}
\hline \multirow[b]{2}{*}{$\begin{array}{c}\text { Sítio } \\
\text { Primário }\end{array}$} & \multicolumn{3}{|c|}{ Cavidade Acometida } & \multirow[b]{2}{*}{ Total } \\
\hline & $\begin{array}{c}\text { Peritoneal } \\
\text { N (\%) }\end{array}$ & $\begin{array}{c}\text { Pericárdica } \\
\text { N (\%) }\end{array}$ & $\begin{array}{l}\text { Pleural } \\
\mathrm{N}(\%)\end{array}$ & \\
\hline Adrenal & 0 & 0 & $1(0,1)$ & $1(0,1)$ \\
\hline Colo Uterino & $6(0,8)$ & 0 & $4(0,4)$ & $10(0,6)$ \\
\hline Intestino & $20(2,7)$ & 0 & $18(1,9)$ & $38(2,3)$ \\
\hline Endométrio & $34(4,7)$ & $1(50,0)$ & $17(1,8)$ & $52(3,1)$ \\
\hline Esôfago & $1(0,1)$ & 0 & $1(0,1)$ & $2(0,1)$ \\
\hline Estômago & $173(23,8)$ & 0 & $6(0,6)$ & $179(10,7)$ \\
\hline Fígado & $9(1,2)$ & 0 & $7(0,7)$ & $16(1,0)$ \\
\hline Indeterminado & $62(8,5)$ & 0 & $54(5,7)$ & $116(6,9)$ \\
\hline Mama & $83(11,4)$ & $1(50,0)$ & $586(62,1)$ & $670(40,1)$ \\
\hline Ovário & $306(42,1)$ & 0 & $124(13,1)$ & $430(25,7)$ \\
\hline Pâncreas & $12(1,6)$ & 0 & $24(2,50$ & $36(2,2)$ \\
\hline Parótida & $1(0,1)$ & 0 & $1(0,1)$ & $2(0,1)$ \\
\hline Pulmão & $3(0,4)$ & 0 & $83(8,8)$ & $86(5,1)$ \\
\hline Rim & $1(0,1)$ & 0 & $4(0,4)$ & $5(0,3)$ \\
\hline Tireóide & $2(0,3)$ & 0 & $4(0,4)$ & $6(0,4)$ \\
\hline Tuba Interina & $1(0,1)$ & 0 & $2(0,2)$ & $3(0,2)$ \\
\hline Vagina & $2(0,3)$ & 0 & 0 & $2(0,1)$ \\
\hline Vesícula Biliar & r $11(1,5)$ & 0 & $7(0,7)$ & $18(1,1)$ \\
\hline Total & $727(43,5)$ & $2(0,1)$ & $943(56,4)$ & 1672 \\
\hline
\end{tabular}

sítio primário de um adenocarcinoma apenas pelas características morfológicas, as reações imunocitoquími cas têm contribuído muito para esse fim ${ }^{18}$.

No contexto mundial, tanto a incidência de câncer, quanto as mortes provocadas vêm crescendo

\begin{tabular}{|c|c|c|c|}
\hline \multirow[b]{2}{*}{$\begin{array}{c}\text { Sítio } \\
\text { Primário }\end{array}$} & \multirow[b]{2}{*}{$\begin{array}{l}\text { Total } \\
\text { N (\%) }\end{array}$} & \multicolumn{2}{|c|}{ Diagnóstico Citológico } \\
\hline & & $\begin{array}{c}\text { Positivo } \\
\text { N (\%) }\end{array}$ & $\begin{array}{c}\text { Negativo } \\
\mathbf{N}(\%)\end{array}$ \\
\hline Estômago & $473(40,5)$ & $202(37,3)$ & $271(43,2)$ \\
\hline Ovário & $306(26,2)$ & $205(37,9)$ & $101(16,1)$ \\
\hline Indeterminado & $99(8,5)$ & $39(7,2)$ & $60(9,6)$ \\
\hline Mama & $83(7,1)$ & $31(5,7)$ & $52(8,3)$ \\
\hline Pâncreas & $52(4,5)$ & $15(2,8)$ & $37(5,9)$ \\
\hline Intestino & $44(3,8)$ & $11(2,0)$ & $33(5,3)$ \\
\hline Endométrio & $34(2,9)$ & $13(2,4)$ & $21(3,3)$ \\
\hline Fígado & $34(2,9)$ & $3(0,6)$ & $31(4,9)$ \\
\hline Via Biliar & $13(1,1)$ & $5(0,9)$ & $8(1,3)$ \\
\hline Pulmão & $7(0,6)$ & $6(1,1)$ & $1(0,2)$ \\
\hline Colo Uterino & $6(0,5)$ & $2(0,4)$ & $4(0,6)$ \\
\hline Esôfago & $4(0,3)$ & $3(0,6)$ & $1(0,2)$ \\
\hline Próstata & $3(0,3)$ & $1(0,2)$ & $2(0,3)$ \\
\hline Tireóide & $3(0,3)$ & $2(0,4)$ & $1(0,2)$ \\
\hline $\operatorname{Rim}$ & $2(0,2)$ & 0 & $2(0,3)$ \\
\hline Vagina & $2(0,2)$ & $2(0,4)$ & 0 \\
\hline Adrenal & $1(0,1)$ & 0 & $1(0,2)$ \\
\hline Parótida & $1(0,1)$ & $1(0,2)$ & 0 \\
\hline Tuba Interina & $1(0,1)$ & 0 & $1(0,2)$ \\
\hline Total & $1168(100,0)$ & $541(100,0)$ & $627(100,0)$ \\
\hline
\end{tabular}

continuamente. Em recente editorial sobre o assunto, Coebergh ${ }^{23}$ relata as projeções de novos casos para o ano 2000. Assim, adenocarcinomas colorretais, de mama, próstata e estômago, saltariam de $3.750,3.600,1.750$ e 1.600 casos por ano para 4.300, 4.300, 2.100 e 1.750, respectivamente; causando, no ano 2000, a morte de $2.300,1.650$, 1.100 e 1.400 pacientes, respectivamente. O câncer de pulmão saltaria de 3.600 para 3.950 novos casos e perspectiva de 3.700 mortes. E mbora não haja discriminação do tipo histogenético dessas lesões, sabe-se que grande parte delas é composta de adenocarcinomas.

Para Black et al. ${ }^{24}$, os principais sítios primários de câncer na Europa são: pulmão (21\%), intestinos (13\%), próstata (12\%), estômago e bexiga com 7\% cada para os homens. Nas mulheres, as principais ocorrências são: mama (28\%), intestinos (15\%), pulmão (6\%) e corpo uterino e estômago com 5\% cada.

Devi do ao grande impacto em saúde representado pelo câncer, a precisa identificação dos sítios primários pode representar um poderoso meio de conduta terapêutica ${ }^{25}$. Bedrossian ${ }^{19}$ ressalta alguns fatores cruciais que envolvem a busca do sítio primário de uma neoplasia metastática em cavidade serosa: o tipo celular presente, o tipo de derrame ea rel ação de sexo e idade do paciente. Segundo 


\begin{tabular}{|c|c|c|c|c|}
\hline \multirow[b]{2}{*}{ Sítio } & \multicolumn{3}{|c|}{ Cavidade Acometida } & \multirow[b]{3}{*}{ Total } \\
\hline & Peritoneal & Pericárdica & Pleural & \\
\hline Primário & N (\%) & N (\%) & $\mathrm{N}(\%)$ & \\
\hline Colo Uterino & $2(0,5)$ & 0 & $1(0,2)$ & $3(0,4)$ \\
\hline Intestino & $3(0,8)$ & 0 & $7(1,5)$ & $10(1,2)$ \\
\hline Endométrio & $13(3,4)$ & 0 & $7(1,5)$ & $20(2,4)$ \\
\hline Esôfago & $1(0,3)$ & 0 & 0 & $1(0,1)$ \\
\hline Estômago & $83(21,8)$ & 0 & $6(1,3)$ & $89(10,5)$ \\
\hline Fígado & 0 & 0 & $1(0,2)$ & $1(0,1)$ \\
\hline Indeterminado & $29(7,6)$ & 0 & $38(8,1)$ & $67(7,9)$ \\
\hline Mama & $31(8,1)$ & $1(100,0)$ & $288(61,7)$ & $320(37,7)$ \\
\hline Ovário & $205(53,8)$ & 0 & $54(11,6)$ & $259(30,5)$ \\
\hline Pâncreas & $4(1,0)$ & 0 & $9(1,9)$ & $13(1,5)$ \\
\hline Parótida & $1(0,3)$ & 0 & 0 & $1(0,1)$ \\
\hline Pulmão & $3(0,8)$ & 0 & $47(10,1)$ & $50(5,9)$ \\
\hline $\operatorname{Rim}$ & 0 & 0 & $3(0,6)$ & $3(0,4)$ \\
\hline Tireóide & $1(0,3)$ & 0 & $2(0,4)$ & $3(0,4)$ \\
\hline Tuba Interina & 0 & 0 & $2(0,4)$ & $2(0,2)$ \\
\hline Vagina & $2(0,5)$ & 0 & 0 & $2(0,2)$ \\
\hline Vesícula Biliar & $3(0,8)$ & 0 & $2(0,4)$ & $5(0,6)$ \\
\hline Total & $381(44,9)$ & $1(0,1)$ & $467(55,0)$ & 849 \\
\hline
\end{tabular}

\begin{tabular}{|c|c|c|c|c|c|c|c|c|c|c|}
\hline \multirow{2}{*}{$\begin{array}{l}\text { Sítio } \\
\text { Primário }\end{array}$} & \multicolumn{9}{|c|}{ FAIXA ETÁRIA } & \multirow[b]{2}{*}{ Total } \\
\hline & $0-9$ & $10-19$ & $20-29$ & $30-39$ & $40-49$ & $50-59$ & $60-69$ & $70-79$ & $80+$ & \\
\hline Adrenal & 0 & 0 & 0 & 0 & $1(100,0)$ & 0 & 0 & 0 & 0 & $1(0,1)$ \\
\hline Colo Uterino & 0 & 0 & 0 & 0 & $1(25,0)$ & $2(50,0)$ & 0 & $1(25,0)$ & 0 & $4(0,4)$ \\
\hline Intestino & 0 & 0 & $1(5,6)$ & 0 & $5(27,8)$ & $1(5,6)$ & $8(44,4)$ & $3(16,7)$ & 0 & $18(1,9)$ \\
\hline Endométrio & 0 & 0 & 0 & 0 & $3(17,6)$ & $8(47,1)$ & $5(29,4)$ & $1(5,9)$ & 0 & $17(1,8)$ \\
\hline Esôfago & 0 & 0 & 0 & 0 & 0 & $1(100,0)$ & 0 & 0 & 0 & $1(0,1)$ \\
\hline Estômago & 0 & $1(16,7)$ & 0 & 0 & 0 & $4(66,7)$ & $1(16,7)$ & 0 & 0 & $6(0,6)$ \\
\hline Fígado & $1(14,3)$ & 0 & $1(14,3)$ & 0 & $1(14,3)$ & $3(42,9)$ & 0 & $1(14,3)$ & 0 & $7(0,7)$ \\
\hline Indeterminado & 0 & 0 & 0 & $2(3,7)$ & $4(7,4)$ & $13(24,1)$ & $26(48,1)$ & $9(16,7)$ & 0 & $54(5,7)$ \\
\hline Mama & 0 & 0 & $6(1,0)$ & $69(11,8)$ & $115(19,6)$ & $183(31,2)$ & $142(24,2)$ & $63(10,8)$ & $8(1,4)$ & $586(62,1)$ \\
\hline Ovário & 0 & 0 & $3(2,4)$ & $11(8,9)$ & $40(32,3)$ & $30(24,2)$ & $24(19,4)$ & $9(7,3)$ & $7(5,6)$ & $124(13,1)$ \\
\hline Pâncreas & 0 & 0 & 0 & 0 & $3(12,5)$ & $5(20,8)$ & $11(45,8)$ & $4(16,7)$ & $1(4,2)$ & $24(2,5)$ \\
\hline Parótida & 0 & 0 & 0 & 0 & 0 & 0 & $1(100,0)$ & 0 & 0 & $1(0,1)$ \\
\hline Pulmão & 0 & 0 & $1(1,2)$ & $2(2,4)$ & $9(10,8)$ & $24(28,9)$ & $27(32,5)$ & $20(24,1)$ & 0 & $83(8,8)$ \\
\hline $\operatorname{Rim}$ & 0 & 0 & 0 & $1(25,0)$ & 0 & $2(50,0)$ & $1(25,0)$ & 0 & 0 & $4(0,4)$ \\
\hline Tireóide & 0 & 0 & 0 & $2(50,0)$ & $1(25,0)$ & $1(25,0)$ & 0 & 0 & 0 & $4(0,4)$ \\
\hline Tuba Interina & 0 & 0 & 0 & 0 & 0 & $2(100,0)$ & 0 & 0 & 0 & $2(0,2)$ \\
\hline Vesícula Biliar & 0 & 0 & 0 & 0 & $2(28,6)$ & $2(28,6)$ & $3(42,9)$ & 0 & 0 & $7(0,7)$ \\
\hline Total & $1(0,1)$ & $1(0,1)$ & $12(1,3)$ & $87(9,2)$ & $185(19,6)$ & $281(29,8)$ & $249(26,4)$ & $111(11,8)$ & $16(1,7)$ & 943 \\
\hline
\end{tabular}

ele, essas informações dispensam, em parte, técnicas auxiliares sofisticadas, como imunocitoquímica e microscopia el etrônica.

O objetivo deste estudo foi avaliar a freqüência de adenocarcinomas em derrames cavitários, dis- criminando faixa etária, sexo e tipo de cavi dade: se pleural, peritoneal ou pericárdica. Este painel pode oferecer subsídios para a investigação clínica e orientar a conduta exploratória de sítios primários desconhecidos. 
Tabela 6 - Freqüência de derrames pleurais com exame citológico positivo para adenocarcinomas em mulheres, distribuídos por faixa etária e sítio primário.

\begin{tabular}{|c|c|c|c|c|c|c|c|c|c|}
\hline \multirow{2}{*}{$\begin{array}{c}\text { Sítio } \\
\text { Primário }\end{array}$} & \multicolumn{8}{|c|}{ Faixa Etária } & \multirow[b]{2}{*}{ Total } \\
\hline & $10-19$ & $20-29$ & $30-39$ & $40-49$ & $50-59$ & $60-69$ & $70-79$ & $80+$ & \\
\hline Colo Uterino & 0 & 0 & 0 & 0 & $1(100,0)$ & 0 & 0 & 0 & $1(0,2)$ \\
\hline Intestino & 0 & 0 & 0 & $1(14,3)$ & $1(14,3)$ & $4(57,1)$ & $1(14,3)$ & 0 & $7(1,5)$ \\
\hline Endométrio & 0 & 0 & 0 & $2(28,6)$ & $3(42,9)$ & $1(14,3)$ & $1(14,3)$ & 0 & $7(1,7)$ \\
\hline Estômago & $1(16,7)$ & 0 & 0 & 0 & $4(66,7)$ & $1(16,7)$ & 0 & 0 & $6(1,3)$ \\
\hline Fígado & 0 & 0 & 0 & $1(100,0)$ & 0 & 0 & 0 & 0 & $1(0,2)$ \\
\hline Indeterminado & 0 & 0 & $2(5,3)$ & 0 & $7(18,4)$ & $22(57,9)$ & $7(18,4)$ & 0 & $38(8,1)$ \\
\hline Mama & 0 & $3(1,0)$ & $27(9,4)$ & $61(21,2)$ & $101(35,1)$ & $69(24,0)$ & $24(8,3)$ & $3(1,0)$ & $288(61,7)$ \\
\hline Ovário & 0 & 0 & $3(5,6)$ & $21(38,9)$ & $16(29,6)$ & $11(20,4)$ & $1(1,9)$ & $2(3,7)$ & $54(11,6)$ \\
\hline Pâncreas & 0 & 0 & 0 & $1(11,1)$ & $1(11,1)$ & $6(66,7)$ & 0 & $1(11,1)$ & $9(1,9)$ \\
\hline Pulmão & 0 & 0 & $2(4,3)$ & $6(12,8)$ & $14(29,8)$ & $17(36,2)$ & $8(17,0)$ & 0 & $47(10,1)$ \\
\hline $\operatorname{Rim}$ & 0 & 0 & $1(33,3)$ & 0 & $1(33,3)$ & $1(33,3)$ & 0 & 0 & $3(0,6)$ \\
\hline Tireóide & 0 & 0 & $2(100,0)$ & 0 & 0 & 0 & 0 & 0 & $2(0,4)$ \\
\hline Tuba Interina & 0 & 0 & 0 & 0 & $2(100,0)$ & 0 & 0 & 0 & $2(0,4)$ \\
\hline Vesícula Biliar & 0 & 0 & 0 & $1(50,0)$ & 0 & $1(50,0)$ & 0 & 0 & $2(0,4)$ \\
\hline Total & $1(0,2)$ & $3(0,6)$ & $37(7,9)$ & $94(20,1)$ & $151(32,3)$ & $133(28,5)$ & $42(9,0)$ & $6(1,3)$ & 467 \\
\hline
\end{tabular}

\begin{tabular}{|c|c|c|c|c|c|c|c|c|c|}
\hline \multirow{2}{*}{$\begin{array}{c}\text { Sítio } \\
\text { Primário }\end{array}$} & \multicolumn{8}{|c|}{ Faixa Etária } & \multirow[b]{2}{*}{ Total } \\
\hline & $10-19$ & $20-29$ & $30-39$ & $40-49$ & $50-59$ & $60-69$ & $70-79$ & $80+$ & \\
\hline Colo Uterino & 0 & 0 & $1(16,7)$ & $2(33,3)$ & $3(50,0)$ & 0 & 0 & 0 & $6(0,8)$ \\
\hline Intestino & 0 & $2(10,0)$ & $3(15,0)$ & $2(10,0)$ & $6(31,0)$ & $5(25,0)$ & $1(5,0)$ & $1(5,0)$ & $20(2,8)$ \\
\hline Endométrio & 0 & $2(5,9)$ & 0 & $1(2,9)$ & $11(32,4)$ & $13(38,2)$ & $5(14,7)$ & $2(5,9)$ & $34(4,7)$ \\
\hline Esôfago & 0 & $1(100,0)$ & 0 & 0 & 0 & 0 & 0 & 0 & $1(0,1)$ \\
\hline Estômago & $1(0,6)$ & $6(3,5)$ & $11(6,4)$ & $34(19,7)$ & $31(17,9)$ & $56(32,4)$ & $27(15,6)$ & $7(4,0)$ & $173(23,8)$ \\
\hline Fígado & 0 & 0 & 0 & $1(11,1)$ & $1(11,1)$ & $7(77,8)$ & 0 & 0 & $9(1,2)$ \\
\hline Indeterminado & 0 & $1(1,6)$ & $2(3,2)$ & $7(11,3)$ & $15(24,2)$ & $25(40,3)$ & $12(19,4)$ & 0 & $62(8,5)$ \\
\hline Mama & 0 & $2(2,4)$ & $10(12,0)$ & $29(34,9)$ & $16(19,3)$ & $20(24,1)$ & $6(7,2)$ & 0 & $83(11,4)$ \\
\hline Ovário & $5(1,6)$ & $14(4,6)$ & $23(7,5)$ & $65(21,2)$ & $95(31,0)$ & $71(23,2)$ & $30(9,8)$ & $3(1,0)$ & $306(42,1)$ \\
\hline Pâncreas & 0 & 0 & 0 & 0 & $2(16,7)$ & $6(50,0)$ & $4(33,3)$ & 0 & $12(1,7)$ \\
\hline Parótida & 0 & 0 & 0 & $1(100,0)$ & 0 & 0 & 0 & 0 & $1(0,1)$ \\
\hline Pulmão & 0 & 0 & 0 & 0 & $1(33,3)$ & $1(33,3)$ & $1(33,3)$ & 0 & $3(0,4)$ \\
\hline Rim & 0 & 0 & $1(100,0)$ & 0 & 0 & 0 & 0 & 0 & $1(0,1)$ \\
\hline Tireóide & 0 & 0 & 0 & 0 & $1(50,0)$ & $1(50,0)$ & 0 & 0 & $2(0,3)$ \\
\hline Tuba Interina & 0 & 0 & 0 & 0 & 0 & $1(100,0)$ & 0 & 0 & $1(0,1)$ \\
\hline Vagina & $1(50,0)$ & 0 & 0 & 0 & 0 & $1(50,0)$ & 0 & 0 & $2(0,3)$ \\
\hline Vesícula Biliar & 0 & 0 & $1(9,1)$ & $2(18,2)$ & $1(9,1)$ & $5(45,5)$ & $1(9,1)$ & $1(9,1)$ & $11(1,5)$ \\
\hline Total & $7(1,0)$ & $28(3,9)$ & $52(7,2)$ & $144(19,8)$ & $183(25,2)$ & $212(29,2)$ & $87(12,0)$ & $14(1,9)$ & 727 \\
\hline
\end{tabular}

\section{MATERIAIS E MÉTODOS}

\section{Seleção da Casuística}

A identificação dos casos de derrames cavitários foi realizada através da consulta aos registros do Departamento de Anatomia Patológica do Hospital A.C. Camargo, entre os anos de 1966 e 1990.

O protocolo inicial de relação continha informações sobre o número do caso no Departamento, o número do registro hospitalar, sexo, idade do paciente, tipo de derrame (se pleural, peritoneal, ou ascítico, ou pericárdico) e o diagnóstico citológico (à época, dado pel a classificação de Papanicolaou).

\section{Consulta aos prontuários}

A pós a identificação de todos os casos, o estudo prosseguiu com a avaliação dos dados clínicolaboratoriais contidos nos prontuários dos pacientes, consultados a partir do número do registro obtido no protocolo inicial. O protocolo dessa consulta ressaltou os seguintes itens:

- Confirmação dos dados obti dos no protocol o inicial - Classificação do tipo da lesão: se neoplásica (maligna ou benigna) ou não-neoplásica - Diagnóstico histopatológico 


\begin{tabular}{|c|c|c|c|c|c|c|c|c|c|}
\hline \multirow{2}{*}{$\begin{array}{c}\text { Sítio } \\
\text { Primário }\end{array}$} & \multicolumn{8}{|c|}{ F aixa Etária } & \multirow[b]{2}{*}{ Total } \\
\hline & $10-19$ & $20-29$ & $30-39$ & $40-49$ & $50-59$ & $60-69$ & $70-79$ & $80+$ & \\
\hline Colo Uterino & 0 & 0 & 0 & $1(50,0)$ & $1(50,0)$ & 0 & 0 & 0 & $2(0,5)$ \\
\hline Intestino & 0 & 0 & 0 & 0 & $2(66,7)$ & $1(33,3)$ & 0 & 0 & $3(0,8)$ \\
\hline Endométrio & 0 & 0 & 0 & 0 & $5(38,5)$ & $6(46,2)$ & $2(15,4)$ & 0 & $13(3,4)$ \\
\hline Esôfago & 0 & $1(100,0)$ & 0 & 0 & 0 & 0 & 0 & 0 & $1(0,3)$ \\
\hline Estômago & $1(1,2)$ & $5(6,0)$ & $6(7,2)$ & $18(21,7)$ & $17(20,5)$ & $24(28,9)$ & $8(9,6)$ & $4(4,8)$ & $83(21,8)$ \\
\hline Indeterminado & 0 & $1(3,4)$ & $1(3,4)$ & $2(6,9)$ & $6(20,7)$ & $14(48,3)$ & $5(17,2)$ & 0 & $29(7,6)$ \\
\hline Mama & 0 & 0 & $2(6,5)$ & $11(35,5)$ & $9(29,0)$ & $6(19,4)$ & $3(9,7)$ & 0 & $31(8,1)$ \\
\hline Ovário & $2(1,0)$ & $10(4,9)$ & $14(6,8)$ & $42(20,5)$ & $69(33,7)$ & $51(24,9)$ & $15(7,3)$ & $2(1,0)$ & $205(53,8)$ \\
\hline Pâncreas & 0 & 0 & 0 & 0 & $2(50,0)$ & $2(50,0)$ & 0 & 0 & $4(1,0)$ \\
\hline Parótida & 0 & 0 & 0 & $1(100,0)$ & 0 & 0 & 0 & 0 & $1(0,3)$ \\
\hline Pulmão & 0 & 0 & 0 & 0 & $1(33,3)$ & $1(33,3)$ & $1(33,3)$ & 0 & $3(0,8)$ \\
\hline Tireóide & 0 & 0 & 0 & 0 & $1(100,0)$ & 0 & 0 & 0 & $1(0,3)$ \\
\hline Vagina & $1(50,0)$ & 0 & 0 & 0 & 0 & $1(50,0)$ & 0 & 0 & $2(0,5)$ \\
\hline Vesícula Biliar & 0 & 0 & $1(33,3)$ & 0 & 0 & $2(66,7)$ & 0 & 0 & $3(0,8)$ \\
\hline Total & $4(1,0)$ & $17(4,5)$ & $24(6,3)$ & $75(19,7)$ & $113(29,7)$ & $108(28,3)$ & $34(8,9)$ & $6(1,6)$ & 381 \\
\hline
\end{tabular}

\begin{tabular}{|c|c|c|c|c|}
\hline \multirow[b]{2}{*}{$\begin{array}{c}\text { Sítio } \\
\text { Primário }\end{array}$} & \multicolumn{3}{|c|}{ Cavidade Acometida } & \multirow[b]{2}{*}{ Total } \\
\hline & $\begin{array}{c}\text { Peritoneal } \\
\text { N (\%) }\end{array}$ & $\begin{array}{c}\text { Pericárdica } \\
\text { N (\%) }\end{array}$ & $\begin{array}{c}\text { Pleural } \\
\mathrm{N}(\%)\end{array}$ & \\
\hline Adrenal & $1(0,2)$ & 0 & $2(1,0)$ & $3(0,5)$ \\
\hline Intestino & $24(5,4)$ & 0 & $10(4,9)$ & $34(5,3)$ \\
\hline Esôfago & $3(0,7)$ & 0 & $2(1,0)$ & $5(0,8)$ \\
\hline Estômago & $300(68,0)$ & 0 & $14(6,9)$ & $314(48,7)$ \\
\hline Fígado & $25(5,7)$ & 0 & $8(3,9)$ & $33(5,1)$ \\
\hline Indeterminado & $37(8,3)$ & 0 & $19(9,3)$ & $56(8,7)$ \\
\hline Pâncreas & $40(9,1)$ & 0 & $16(7,9)$ & $56(8,7)$ \\
\hline Parótida & 0 & 0 & $2(1,0)$ & $2(0,3)$ \\
\hline Próstata & $3(0,7)$ & 0 & $9(4,4)$ & $12(1,9)$ \\
\hline Pulmão & $4(0,9)$ & $1(100,0)$ & $102(50,2)$ & $107(16,6)$ \\
\hline Rim & $1(0,2)$ & 0 & $10(4,9)$ & $11(1,7)$ \\
\hline Tireóide & $1(0,2)$ & 0 & $3(1,5)$ & $4(0,6)$ \\
\hline Vesícula Biliar & $2(0,4)$ & 0 & $6(2,9)$ & $8(1,2)$ \\
\hline Total & $441(68,4)$ & $1(0,2)$ & $203(31,5)$ & 645 \\
\hline
\end{tabular}

- I dentificação do sítio primário da lesão

- Dados do seguimento clínico que corroborassem os diagnósticos cito-histopatológicos.

\section{RESULTADOS}

Foram analisadas 4.297 amostras de 3.379 pacientes. Destas, 3.785 amostras $(88,1 \%)$ correspondiam a casos comprovados de associação com neoplasia maligna e 512 de outras doenças.

Dentre os casos de câncer, 2.317 tinham diagnóstico de adenocarcinoma. A tabela 1 mostra a freqüência de derrames pleurais associados a adenocarcinomas, discriminando os diagnósticos citológicos positivos e negativos para malignidade,
Tabela 10-Freqüência de derrames cavitários citologicamente positivos para adenocarcinoma em homens, distribuídos por sítios primários.

\begin{tabular}{|c|c|c|c|c|}
\hline \multirow[b]{2}{*}{$\begin{array}{c}\text { Sítio } \\
\text { Primário }\end{array}$} & \multicolumn{3}{|c|}{ Cavidade Acometida } & \multirow[b]{2}{*}{ Total } \\
\hline & $\begin{array}{c}\text { Peritoneal } \\
\text { N (\%) }\end{array}$ & $\begin{array}{c}\text { Pericárdica } \\
\text { N (\%) }\end{array}$ & $\begin{array}{c}\text { Pleural } \\
\mathbf{N}(\%)\end{array}$ & \\
\hline Adrenal & 0 & 0 & $1(100,0)$ & $1(0,4)$ \\
\hline Intestino & $8(72,7)$ & 0 & $3(27,3)$ & $11(4,4)$ \\
\hline Esôfago & $2(50,0)$ & 0 & $2(50,0)$ & $4(1,6)$ \\
\hline Estômago & $119(90,2)$ & 0 & $13(9,8)$ & $132(53,0)$ \\
\hline Fígado & $3(60,0)$ & 0 & $2(40,0)$ & $5(2,0)$ \\
\hline Indeterminado & $10(52,6)$ & 0 & $9(47,4)$ & $19(7,6)$ \\
\hline Pâncreas & $11(84,6)$ & 0 & $2(15,4)$ & $13(5,2)$ \\
\hline Parótida & 0 & 0 & $1(100,0)$ & $1(0,4)$ \\
\hline Próstata & $1(50,0)$ & 0 & $1(50,0)$ & $2(0,8)$ \\
\hline Pulmão & $3(6,1)$ & $1(2,0)$ & $45(91,8)$ & $49(19,7)$ \\
\hline $\operatorname{Rim}$ & 0 & 0 & $4(100,0)$ & $4(1,6)$ \\
\hline Tireóide & $1(33,3)$ & 0 & $2(66,7)$ & $3(1,2)$ \\
\hline Vesícula Biliar & $2(40,0)$ & 0 & $3(60,0)$ & $5(2,0)$ \\
\hline Total & $160(64,3)$ & $1(0,4)$ & $88(35,3)$ & 249 \\
\hline
\end{tabular}

distribuídos por sítio primário. A tabela 2 mostra tal distribuição em amostras de líquidos ascíticos. Apenas três casos de derrame pericárdico foram observados: um de endométrio, em paciente de 35 anos, com citológico negativo para malignidade; uma paciente com adenocarcinoma de mama, 75 anos, com citologia positiva; e um homem com adenocarcinoma de pulmão, 52 anos e citológico positivo para neoplasia.

As tabelas 3 e 4 mostram as freqüências de derrames cavitários em mulheres associados a adenocarcinomas. A tabela 3 apresenta o conjunto dos exames citológicos associados a adenocarcinomas e a tabela 4 mostra apenas os positivos para malignidade. Destaque-se que em derrames 


\begin{tabular}{|c|c|c|c|c|c|c|c|c|}
\hline \multirow{2}{*}{$\begin{array}{c}\text { Sítio } \\
\text { Primário }\end{array}$} & \multicolumn{7}{|c|}{ F aixa Etária } & \multirow[b]{2}{*}{ Total } \\
\hline & $20-29$ & $30-39$ & $40-49$ & $50-59$ & $60-69$ & $70-79$ & $80+$ & \\
\hline Adrenal & 0 & 0 & 0 & $2(100,0)$ & 0 & 0 & 0 & $2(1,0)$ \\
\hline Intestino & $1(10,0)$ & 0 & $2(20,0)$ & 0 & $6(60,0)$ & $1(10,0)$ & 0 & $10(4,9)$ \\
\hline Esôfago & 0 & 0 & 0 & 0 & $2(100,0)$ & 0 & 0 & $2(1,0)$ \\
\hline Estômago & 0 & $2(14,3)$ & $3(21,4)$ & $5(35,7)$ & $4(28,6)$ & 0 & 0 & $14(6,9)$ \\
\hline Fígado & $1(12,5)$ & 0 & $3(37,5)$ & $2(25,0)$ & 0 & $2(25,0)$ & 0 & $8(3,9)$ \\
\hline Indeterminado & $2(10,5)$ & $3(15,8)$ & $3(15,8)$ & $4(21,1)$ & $3(15,8)$ & $3(15,8)$ & $1(5,3)$ & $19(9,4)$ \\
\hline Pâncreas & 0 & 0 & $4(24,0)$ & $5(31,3)$ & $3(18,8)$ & $4(25,0)$ & 0 & $16(7,9)$ \\
\hline Parótida & 0 & 0 & 0 & 0 & $2(100,0)$ & 0 & 0 & $2(1,0)$ \\
\hline Próstata & 0 & 0 & 0 & $4(44,4)$ & $4(44,4)$ & $1(11,1)$ & 0 & $9(4,4)$ \\
\hline Pulmão & $1(1,0)$ & $3(2,9)$ & $10(9,8)$ & $36(35,3)$ & $30(29,4)$ & $20(19,6)$ & $2(2,0)$ & $102(50,2)$ \\
\hline Rim & 0 & $1(10,0)$ & 0 & $4(40,0)$ & $4(40,0)$ & $1(10,0)$ & 0 & $10(4,9)$ \\
\hline Tireóide & 0 & $1(33,3)$ & 0 & $1(33,3)$ & 0 & $1(33,3)$ & 0 & $3(1,5)$ \\
\hline Vesícula Biliar & 0 & 0 & 0 & $2(33,3)$ & $2(33,3)$ & $1(16,7)$ & $1(16,7)$ & $6(3,0)$ \\
\hline Total & $5(2,5)$ & $10(4,9)$ & $25(12,3)$ & $65(32,0)$ & $60(29,6)$ & $34(16,7)$ & $4(2,0)$ & 203 \\
\hline
\end{tabular}

\begin{tabular}{|c|c|c|c|c|c|c|c|c|}
\hline \multirow{2}{*}{$\begin{array}{c}\text { Sítio } \\
\text { Primário }\end{array}$} & \multicolumn{7}{|c|}{ Faixa Etária } & \multirow[b]{2}{*}{ Total } \\
\hline & $20-29$ & $30-39$ & $40-49$ & $50-59$ & $60-69$ & $70-79$ & $80+$ & \\
\hline Adrenal & 0 & 0 & 0 & 1 & 0 & 0 & 0 & $1(1,1)$ \\
\hline Intestino & $1(33,3)$ & 0 & $1(33,3)$ & 0 & $1(33,3)$ & 0 & 0 & $3(3,4)$ \\
\hline Esôfago & 0 & 0 & 0 & 0 & $2(100,0)$ & 0 & 0 & $2(2,3)$ \\
\hline Estômago & 0 & $2(15,4)$ & $3(23,1)$ & $4(30,8)$ & $4(30,8)$ & 0 & 0 & $13(14,8)$ \\
\hline Fígado & 0 & 0 & $1(50,0)$ & $1(50,0)$ & 0 & 0 & 0 & $2(2,3)$ \\
\hline Indeterminado & $1(11,1)$ & $1(11,1)$ & $1(11,1)$ & $2(22,2)$ & $1(11,1)$ & $2(22,2)$ & $1(11,1)$ & $9(10,2)$ \\
\hline Pâncreas & 0 & 0 & 0 & $2(100,0)$ & 0 & 0 & 0 & $2(2,3)$ \\
\hline Parótida & 0 & 0 & 0 & 0 & $1(100,0)$ & 0 & 0 & $1(1,1)$ \\
\hline Próstata & 0 & 0 & 0 & $1(100,0)$ & 0 & 0 & 0 & $1(1,1)$ \\
\hline Pulmão & $1(2,2)$ & $1(2,2)$ & $5(11,1)$ & $14(31,1)$ & $17(37,8)$ & $6(13,3)$ & $1(2,2)$ & $45(51,1)$ \\
\hline Rim & 0 & 0 & 0 & 0 & $4(100,0)$ & 0 & 0 & $4(4,5)$ \\
\hline Tireóide & 0 & 0 & 0 & $1(50,0)$ & 0 & $1(50,0)$ & 0 & $2(2,3)$ \\
\hline Vesícula Biliar & 0 & 0 & 0 & $1(33,3)$ & $1(33,3)$ & $1(33,3)$ & 0 & $3(3,4)$ \\
\hline Total & $3(3,4)$ & $4(4,5)$ & $11(12,5)$ & $27(30,7)$ & $31(35,2)$ & $10(11,4)$ & $2(2,3)$ & 88 \\
\hline
\end{tabular}

pl eurais, 586 de 943 casos (62,1\%) estavam associados a adenocarcinoma de mama, sendo o adenocarcinoma de ovário o segundo mais freqüente $(124 / 943=13,1 \%)$.

Em peritônio, o sítio primário mais freqüente foi o ovário (306/727 =42,1\%), seguido pel o de estômago $(173 / 727=23,8 \%)$. Esses dados mantêm-se nas amostras pleurais citologicamente positivas para malignidade, com 288 em 467 casos de mama $(61,7 \%)$ e 54 de 467 de ovário (11,6\%). Em derrames peritoneais, observaram-se 205 casos de adenocarcinoma de ovário em 381 (53,8\%) com citologia positiva; e 83 de estômago em 381 (21,8\%) exames.

A tabela 5 mostra o conjunto de exames de derrames pleurais em mulheres associados a adenocarcinomas, distribuídos por faixa etária e sítio primário, observando-se na tabela 6 tal distribui- ção nos exames citológicos positivos para malignidade. Os adenocarcinomas primitivos de mama e ovário apresentam-se mais freqüentes em mulheres nas faixas etárias entre 40-69 anos, em ambas as tabelas. Os primitivos de mama apresentam maior ocorrência entre os 50-59 anos e os de ovário entre os 40-49 anos.

A tabela 7 apresenta a distribuição por faixa etária e síti o primário de derrames peritoneais em mulheres, sendo os exames positivos para neoplasi a expostos na tabela 8 . N essa cavidade (Tabela 7) observamos a predominância da associação com adenocarci nomas de ovário ( $42,1 \%$ dos casos), seguidos pelos de estômago (23,8\%) e mama $(11,4 \%)$. Seguindo a mesma tendência observada nos derrames pleurais, a faixa etária mais freqüente foi a de 40-69 anos, com máxima expressão entre 50-59 anos para as metástases de ovário e 40- 
Tabela 13-Freqüência de derrames peritoneais associados a adenocarcinomas em homens, distribuídos por faixa etária e sítio primário.

\begin{tabular}{|c|c|c|c|c|c|c|c|c|c|c|}
\hline \multirow{2}{*}{$\begin{array}{c}\text { Sítio } \\
\text { Primário }\end{array}$} & \multicolumn{9}{|c|}{ F aixa Etária } & \multirow[b]{2}{*}{ Total } \\
\hline & $0-9$ & $10-19$ & $20-29$ & $30-39$ & $40-49$ & $50-59$ & $60-69$ & $70-79$ & $80+$ & \\
\hline Adrenal & 0 & 0 & 0 & 0 & 0 & $1(100,0)$ & 0 & 0 & 0 & $1(0,2)$ \\
\hline Intestino & 0 & $3(12,5)$ & $2(8,3)$ & $1(4,2)$ & $2(8,3)$ & $2(8,3)$ & $9(37,5)$ & $4(16,7)$ & $1(4,2)$ & $24(5,4)$ \\
\hline Esôfago & 0 & 0 & 0 & 0 & $1(33,3)$ & $2(66,7)$ & 0 & 0 & 0 & $3(0,7)$ \\
\hline Estômago & 0 & 0 & $1(0,3)$ & $12(4,0)$ & $49(16,3)$ & $92(30,7)$ & $88(29,3)$ & $49(16,3)$ & $9(3,0)$ & $300(68,0)$ \\
\hline Fígado & 0 & 0 & $7(28,0)$ & $1(4,0)$ & $4(16,0)$ & $6(24,0)$ & $4(16,0)$ & $3(12,0)$ & 0 & $25(5,7)$ \\
\hline Indeterminado & $1(2,7)$ & 0 & $1(2,7)$ & $4(10,8)$ & $4(10,8)$ & $10(27,0)$ & $16(43,2)$ & 0 & $1(2,7)$ & $37(8,4)$ \\
\hline Pâncreas & 0 & 0 & 0 & 0 & $6(15,0)$ & $11(27,5)$ & $17(42,5)$ & $6(15,0)$ & 0 & $40(9,1)$ \\
\hline Próstata & 0 & 0 & 0 & 0 & 0 & 0 & $2(66,7)$ & $1(33,3)$ & 0 & $3(0,7)$ \\
\hline Pulmão & 0 & 0 & 0 & 0 & $2(50,0)$ & $1(25,0)$ & 0 & $1(25,0)$ & 0 & $4(0,9)$ \\
\hline Rim & 0 & 0 & 0 & 0 & 0 & 0 & 0 & $1(100,0)$ & 0 & $1(0,2)$ \\
\hline Tireóide & 0 & 0 & 0 & 0 & 0 & 0 & 0 & $1(100,0)$ & 0 & $1(0,2)$ \\
\hline Vesícula Biliar & 0 & 0 & 0 & 0 & 0 & 0 & $1(50,0)$ & $1(50,0)$ & 0 & $2(0,5)$ \\
\hline Total & $1(0,2)$ & $3(0,7)$ & $11(2,5)$ & $18(4,1)$ & $68(15,4)$ & $125(28,3)$ & $137(31,1)$ & $67(15,2)$ & $11(2,5)$ & 441 \\
\hline
\end{tabular}

Tabela 14 - Freqüência de derrames peritoneais com exame citológico positivo para adenocarcinoma em homens, distribuídos por faixa etária e sítio primário.

\begin{tabular}{|c|c|c|c|c|c|c|c|c|c|c|}
\hline \multirow{2}{*}{$\begin{array}{c}\text { Sítio } \\
\text { Primário }\end{array}$} & \multicolumn{9}{|c|}{ Faixa Etária } & \multirow[b]{2}{*}{ Total } \\
\hline & $0-9$ & $10-19$ & $20-29$ & $30-39$ & $40-49$ & $50-59$ & $60-69$ & $70-79$ & $80+$ & \\
\hline Intestino & 0 & $1(12,5)$ & 0 & $1(12,5)$ & $1(12,5)$ & 0 & $3(37,5)$ & $2(25,0)$ & 0 & $8(5,0)$ \\
\hline Esôfago & 0 & 0 & 0 & 0 & $1(50,0)$ & $1(50,0)$ & 0 & 0 & 0 & $2(1,3)$ \\
\hline Estômago & 0 & 0 & $1(0,8)$ & $3(2,5)$ & $20(16,8)$ & $39(32,8)$ & $36(30,3)$ & $14(11,8)$ & $6(5,0)$ & $119(74,4)$ \\
\hline Fígado & 0 & 0 & 0 & $1(33,3)$ & $1(33,3)$ & 0 & $1(33,3)$ & 0 & 0 & $3(1,9)$ \\
\hline Indeterminado & $1(10,0)$ & 0 & 0 & $1(10,0)$ & $2(20,0)$ & $4(40,0)$ & $2(20,0)$ & 0 & 0 & $10(6,3)$ \\
\hline Pâncreas & 0 & 0 & 0 & 0 & $1(9,1)$ & $3(27,3)$ & $6(54,5)$ & $1(9,1)$ & 0 & $11(6,9)$ \\
\hline Próstata & 0 & 0 & 0 & 0 & 0 & 0 & $1(100,0)$ & 0 & 0 & $1(0,6)$ \\
\hline Pulmão & 0 & 0 & 0 & 0 & $2(66,7)$ & 0 & 0 & $1(33,3)$ & 0 & $3(1,9)$ \\
\hline Tireóide & 0 & 0 & 0 & 0 & 0 & 0 & 0 & $1(100,0)$ & 0 & $1(0,6)$ \\
\hline Vesícula Biliar & 0 & 0 & 0 & 0 & 0 & 0 & $1(50,0)$ & $1(50,0)$ & 0 & $2(1,3)$ \\
\hline Total & $1(0,6)$ & $1(0,6)$ & $1(0,6)$ & $6(3,8)$ & $28(17,5)$ & $47(29,4)$ & $50(31,3)$ & $20(12,5)$ & $6(3,8)$ & 160 \\
\hline
\end{tabular}

49 anos para as de mama, ao contrário dos derrames pleurais. Os adenocarcinomas de estômago mostraram maior freqüência entre os 60 e 69 anos.

Essa tendência de freqüências foi igualmente observada nos casos de derrames citologicamente positivos para células neoplásicas (Tabela 8).

Tanto em derrames pleurais quanto em peritoneais, os casos de sítios primários indeterminados em mulheres apresentaram significativas freqüências de $5,7 \%$ e $8,1 \%$, nas tabelas 5 e 6 , respectivamente; e de $8,5 \%$ e $7,6 \%$ nas tabelas 7 e 8 , respectivamente.

Nos homens, as tabelas 9 e 10 mostram as freqüências de derrames cavitários, distribuídas por cavidades e pelos sítios primários. A tabela 9 mostra o conjunto de amostras, e na tabela 10 são apresentados apenas os exames positivos para neoplasia. É notória a maior freqüência de derrames associados aos adenocarcinomas de estômago com 48,7\% (Tabela 9) e 53\% (Tabela 10), se consi- derados os totais de derrames. Esses dados são seguidos de altas freqüências de derrames associados aos adenocarcinomas de pulmão com 16,6\% (Tabel a 9) do conjunto de casos e 19,7\% se considerados apenas os casos positivos para malignidade.

Esses índices ficam mais claros se considerarmos as informações contidas nas tabel as 11 e 12, onde as freqüências de derrames pleurais associados a adenocarcinomas de vários sítios (total na tabela 11 e apenas os positivos na tabela 12), divididos por faixa etária.

$\mathrm{Na}$ tabela 11 , observamos que $50,2 \%$ dos casos de derrames pleurais em homens estão associados a adenocarcinoma de pulmão, repetindo-se índice semelhante, $51,1 \%$ (Tabela 12) nos casos citologicamente positivos. As faixas etárias de maior acometimento cavitário por metástases de adenocarcinomas em homens são as de 50-59 anos e 60-69 anos, notando-se que nos exames com diagnósti co citológi co de adenocarcinoma, 37,8\% estão 
na faixa de 60-69 anos (Tabela 12).

N ota-se, também, a el evada ocorrência de casos de sítio primário indeterminado 9,4\% (Tabela 11) em 10,2\% das amostras positivas (Tabela 12 ); além dos casos de adenocarcinomas de estômago, onde os casos citol ogicamente positivos chegam a $14,8 \%$ (Tabela 12).

Em derrames peritoneais, observou-se expressiva predominância de casos associados aos adenocarcinomas de estômago, com $68 \%$ do conjunto de casos (Tabela 13) e 74,4\% nos casos com amostras citológi cas positivas para neoplasia (Tabela 14). As faixas etárias com maior ocorrência de casos estão as de 50-59 anos e 60-69 anos, com discreta predominância para o primeiro grupo (Tabelas 13 e 14).

Os derrames peritoneais associados aos adenocarcinomas de pâncreas apresentam a segunda mai or freqüência, com 9,1\% e 6,9\% dos casos para as tabelas 13 e 14, respectivamente. Contudo, a faixa etária de maior ocorrência é a de 60-69 anos, tanto para os casos citologicamente negativos e como nos positivos para mal ignidade. À semel hança dos derrames pleurais, os casos de sítios primários indeterminados ainda representam importante ocorrência, com 8,4\% do total de casos (Tabela 13), perfazendo $6,3 \%$ dos derrames pleurais citologicamente positivos para neoplásicos (Tabela 14).

\section{DISCUSSÃO}

A identificação de sítios primários de adenocarci nomas em bases puramente cito-morfológicas não tem apresentado eficiência satisfatória. $\mathrm{Na}$ mulher adulta, os adenocarcinomas de mama, ovário e trato gastrointestinal (TGI) são os mais freqüentes em cavidade pleural; e os de ovário, mama e os de TGI, os mais freqüentes em derrame peritoneal. Nos homens adultos, os derrames pleurais mali gnos são decorrentes, sobretudo, de carcinomas de pulmão (predominantemente adenocarcinomas) e do TGI. Em cavidade peritoneal, a grande porcentagem dos casos malignos são de TGI (estômago, pâncreas, cólon) ${ }^{21,22}$. Independentemente da quantidade de casos das muitas séries publicadas, as neoplasias acima têm se mostrado, de fato, as de maior incidência em derrames cavitários, apesar de algumas variações na ordem de aparecimento ${ }^{9,11,26-29}$.

Em homens, a neoplasia mais freqüente tem sido os adenocarcinomas de pulmão em derrame pleural e os do TGI em ascites 19,21. Em mulheres, as séries de Di Bonito et $a^{10,11}$, em 1992 e 1993, apresentam os carcinomas de mama (38,2\%) seguidos dos de pulmão $(20,6 \%)$ como os mais freqüentes em derrame pleural e as de estômago e ovário em ascites, respectivamente.

Koss $^{21}$ (1997) identifica os carcinomas de ovário como as neoplasias malignas femininas mais freqüentes em derrames cavitários depois dos de mama; na série de Sears \& Hajdu ${ }^{9}$ (1987) o conjunto de derrames acometidos por câncer apresentou maior freqüência dos de mama (24\%), pulmão (19\%) e neoplasias linfoproliferativas (16\%) em pleura; e ovário (32\%), mama (13\%) e neoplasias linfoproliferativas (7\%) em ascites, muito embora haja significativa melhora de desempenho da morfologia com a associ ação de marcadores imunocitoquími $\cos ^{30}$. Alguns relatos, como o de Murphy $\& N^{8}(1972)$, identificaram corretamente $78 \%$ de adenocarcinomas, $46 \%$ dos de ovário e $42 \%$ de pulmão; Spiele® \& Gloor ${ }^{31}$ chegaram a índices semelhantes. Entretanto, a maioria dos resultados tem oscilado em torno de $50 \%$, o que, para al guns autores, não parece suficiente $e^{9,30,32}$.

As freqüências analisadas neste estudo podem servir de parâmetros que podem sugerir ao clínico geral uma abordagem inicial na investigação de possíveis sítios primários, podendo, então, selecionar mel hor a relação custo-benefício dos principais métodos diagnósticos de imagem ou a marcadores tumorais em cada situação específica.

$\mathrm{TaO}^{25}$ (1996), em sua larga experiência de 25 anos e cerca de 15.000 casos analisados, relata como mais comuns as metástases em derrames pleurais de carcinomas de pulmão (embora não discrimine adenocarcinomas), do trato gastrointestinal e do pâncreas para os homens; e mama, pulmão e ovário para as mulheres.

E m nossa série, observamos maior freqüência de derrames pleurais positivos para adenocarcinomas em homens nos seguintes síti os primários: pulmão, estômago e rim; para as mulheres, a freqüência foi : mama, ovário e pâncreas.

E m derrames peritoneais, $\operatorname{TaO}^{25}$ (1996) observou maior freqüência de casos de origem gastrointestinal, pâncreas e pulmão para homens; e ovário, trato gastrointestinal e pâncreas para mulheres. $\mathrm{Na}$ presente série, obtivemos maior freqüência de casos de estômago, pâncreas efígado para homens; e ovário, estômago e mama para mulheres.

Bedrossian ${ }^{19}$ (1994) apresenta casos semel hantes apontando, segundo relato de vários autores, o adenocarcinoma de pulmão como a causa mais freqüente de derrame pleural com células neoplásicas malignas. Para mulheres, o câncer de mama tem se mostrado, consistentemente, o mais freqüente, compondo $62,1 \%$ das neoplasias com derrame pleural na atual casuística. Em derrames peritoneais, os carcinomas de trato gastrointestinal são apontados como os mais comuns em homens; e os de trato genital 
feminino e mais frequente em mulheres ${ }^{19}$.

Derrames pericárdicos neoplásicos não são tão freqüentes como os pleurais e os peritoneais; entretanto, Bedrossian ${ }^{19}$ (1994) relata os casos de adenocarcinomas de mama, cólon e pulmão como os mais comuns, semel hante ao da presente série. A análise da atual casuística aponta os adenocarcinomas de mama, ovário, estômago e pulmão como os mais freqüentes em derrames cavitários. E m cavidade pleural, mama, pulmão e ovário são os mais freqüentes, respectivamente. A rigor, um adenocarcinoma de cavidade pleural de paciente masculino apresenta-se como séri o dilema de identificação de sítio primário. As evidências numéricas apontam o pulmão como o sítio primário mais provável. Em mulheres, há marcante predomínio do adenocarcinoma de mama.

O acometimento de cavidade peritoneal aponta, em mulheres para o ovário e secundariamente para o estômago como os sítios primários mais prováveis. No caso de paciente masculino, essa probabilidade aponta muito sugestivamente para o estômago, devendo, secundariamente, ser avaliada a possível origem pancreática.

\section{CONCLUSÕES}

Os dados obti dos neste estudo, associados às informações clíni cas, podem auxiliar na sel eção dos métodos de investigação de sítios primários de casos de derrames cavitários com diagnóstico citomorfológico de adenocarcinoma, onde o órgão de origem da neoplasia ainda permanece indeterminado.

As expectativas para um futuro próximo são as de um aprimoramento ainda maior, com a análise conjunta dos achados morfológi cos e demais aspectos da patologia molecular e com as novas técnicas de diagnóstico por imagem.

\section{SUMMARY}

\section{Frequency of adenocarcinomas in serous effusions}

BACKGRound. Metastatic adenocarcinomas in effusi ons are frequently observed. Cytologic diagnosis of adenocarcinoma is often precise; unfortunately, theclassification of the primary siteis not possiblein a great number of cases. The scope of this study was to report the frequency of adenocarcinomas in effusions according to the primary site.

Material. We studied 2317 sequential cases: 1146 pleural effusions (943 women and 203 men), 1168 ascitic ( 727 women and 441 men), and 3 pericardial ( 2 women and 1 men).
Method :Retrospective analysis of the records of the patients and correlations of the data of clinical follow up and morphological findings.

RESULTS. The primary sites more frequently seen in pleural cavity were: breast ( $\mathrm{N}=586$ 51.1\%), lung ( $\mathrm{N}=185-16.1 \%: 102$ men and 83 women), and ovary ( $\mathrm{N}=124-10.8 \%)$; in ascites: stomach ( $\mathrm{N}=473-40.5 \%$ : 300 men and 173 women), ovary ( $\mathrm{N}=306-26.2 \%)$ and breast ( $\mathrm{N}=83$ 7.1\%). Regarding only the samples of malignant effusions we observed 555 in pleural cavity: breast ( $\mathrm{N}=288$ - 51.9\%), lung ( $\mathrm{N}=92,16.6 \%$ : 45 men and 47 women) and ovary ( $N=54,9.7 \%)$. In ascites we reported: ovary ( $\mathrm{N}=205-37.9 \%)$, stomach $(\mathrm{N}=202$ - 37,3\%: 119 men and 83 women) and breast ( $N=31$ - 6.8\%). In 47 pleural effusions (8.5\%) and 37 ascites $(6.8 \%)$, the original site of the neoplasia remained undetermined. Conclusion: The knowledge of the relative frequencies, associated with clinical information, can be helpful in the selection of further investigation for the metastatic adenocarcinomas. [Rev Ass Med Bras 1999; 45(4): 327-36]

KEY WORDS: Adenocarcinoma. Serous effusions. Cytopathology. Pleural effusions. Ascites. Metastases.

\section{REFERÊNCIAS BIBLIOGRÁFICAS}

1. Luke, A; Klebs, G; Beitrag, Z. Ovarieotomie und zur kenntnis der abdominalgeschwulste. Virchows Arch. F. Path. Anat., v.41, p.1, 1867. Apud Nieburgs, H.E. Introduction cytologic techniques for office and clinic. New York, Grune \& Stratton, 1.956. p.1-5.

2. Warren, LF. The diagnostic value of mitoticfigures in thecells of serous exsudates. Arch Int Med 1980; 8: 648-58.

3. Goldman, A. Cytology of serous effusions with special reference to the tumor cells. Arch Surg 1929; 19: 1.672-8.

4. Graham, GS. The cancer cells of serous effusions. AmJ Pathol 1993; 9:701-10.

5. Saphir, O. Cytologic diagnosis of cancer from pleural and peritoneal fluids. AmJ Clin Pathol 1949; 19: 309-14.

6. Luse, SA; Reagan, J W. A histological study of effusions. II. Effusions associated with malignant tumors. Cancer 1954; 7: 1.167-81.

7. J ohnson, WD. The cytological diagnosis of cancer in serous effusions. Acta Cytol 1966; 10: 161-72.

8. Murphy, WM; Ng, ABP. Determination of primary site by examination of cancer cells in body fluids. Am J Clin Pathol 1972; 58: 479-88.

9. Sears, D; Hajdu, SI. The cytologic diagnosis of malignant neoplasms in pleural and peritoneal effusions. Acta Cytol 1987; 31: 85-97.

10. Di Bonito, L; Fal conieri, G; Colanti, I et al. Thepositive pleural effusion: a retrospective study of cytopathologic diagnoses with autopsy confirmation. Acta Cytol 1992; 36: 330-2.

11. Di Bonito, L; Falconieri, G; Colanti, I et al. The positive peritoneal effusion: a retrospective study of cytopathologic diagnoses with autopsy confirmation. Acta Cytol 1993; 37: 483-8.

12. Koprovska, I. Exfoliative cytology in the study of ascites tumors. Ann NY Acad Sci 1956; 63: 738-47. 
13. Wojno, KJ ; Olson, J L; Sherman, ME. Cytopathol ogy of pleural effusions after radiotherapy. Acta Cytol 1994; 38: 1-8.

14. Longatto Filho, A; Bisi, H; Bortolan, J et al. Estudo morfológico de adenocarcinomas metastáticos em derrames cavitários. F Med (BR) 1996; 113(1): 41-50.

15. Oyafuso, MS; Longatto-Filho, A; Bortolan, J et al. Cytological diagnosis in serous effusions in a cancer hospital in Brazil. Pathol ogica 1996; 88: 128-31.

16. Boring, CC; Acquires, TS; Tong, T. Cancer Statistics. CA 1993; 43: 7-26.

17. Ringenberg, QS; Doll, DC; Loy, TS et al. Malignant ascites of unknown origin. Cancer 1989; 64: 753-5.

18. Sheahan, K; O'keame, J C; Abramowitz, A et al. Metastatic adenocarcinoma of a unknown primary site: a comparison of the relative contributions of morphology, minimal essential clinical data and CEA immunostaining status. Am J Clin Pathol 1993; 99: 729-35.

19. Bedrossian, CWM. Malignant effusions: a multimodal approach to cytologic diagnosis. I gaku-Shoin, New Y ork, 1994.

20. Yabro, J W. Effusions. In Abel off, MD; Armitage, J O; Lichter, AS; Niederhuber, JE eds. Clinical Oncology, New York, Churchill Linvingstone, 1995; 709-25.

21. Koss, LG. Examination of effusions pleural, ascitic and pericardial fluids. In Bibbo, M; Keeber, CM; Koss, LG; Patten, $\mathrm{SF}$; Rosenthal, DL eds. Compendium on diagnostic cytology, $8^{\text {th }}$ ed. Chicago, Illinois, USA, 1977; 292-4.

22. Schofield, J ; Krausz, T. Metastatic diseaseand lymphomas. In Gray, W ed. Diagnostic Cytopathol ogy, New York, Churchill, 1995; 149-94.

23. Coebergh, J WW. Cancer Burden in Europe for 1990: can we predict the figures for the year 2000? Eur J Cancer 1997; 33: 991-6.
24. Black, RJ ; Bray, F; Ferlay, J et al. Cancer incidence and mortality in the European Union: Cancer registry data and estimates of national incidencefor 1990. EurJ Cancer 1997; 3: 1.075-107.

25. Tao, LC. Cytopathology of malignant effusions: cytomorphol ogic interpretation. ASCP, Hong Kong, 1996.

26. Vignale, L; Galli, G; Rossi, PC et al. L'esame citologico del líquido pelurico nella diagnostica delle pleutiti neoplastiche. Minerva Med 1990; 81:455-9.

27. J ohnston, WW; Azpak, CA; Lottich, SC et al. Use of a monoclonal antibody (B 72.3) as an immunocytochemical adjunct to diagnosis of adenocarcinoma im human effusions. Cancer Res 1985; 45: 1.894-900.

28. Lopez Cardozo, P. A critical evaluation of 3000 cytologic analysis of pleural fluid, ascitic fluid and pericardial fluid. Acta Cytol 1966; 10:455-60.

29. Fleming, ID; Phillips, J L; Menck, HR et al. The National Cancer Data Base Report on recent hospital cancer progress toward complete american joint committee on Cancer/TNM staging. Cancer 1997; 80: 2305-10.

30. Longatto-Filho, A; Bisi, H; Alves, VAF et al. Adenocarcinoma in female detected in serous effusions. Cytomorphologic aspects and immunocytochemical reactivity to cytokeratins 7 and 20. Acta Cytol 1997; 41: 961-71.

31. Spieler, P; Gloor, F. I dentification of types and primary sites of malignant tumors by examination of exfoliated tumor cells in serous fluids: Comparison with the diagnostic accuracy on small histologic biopsies. Acta Cytol 1985; 29: 753-67.

32. Naylor, B. Pleural, peritoneal and pericardial fluid. In Bibbo, $M$ ed. Comprehensive Cytopathology, 2nd ed. Philadelphia, W.B. Saunders, 1997; 541-610. 